\title{
Impact of a plant-based diet on behavioural and physiological traits in sea bass (Dicentrarchus labrax)
}

\author{
David BENHAÏM ${ }^{1, a}$, Marie-Laure BÉGOUT ${ }^{2}$, Samuel PÉAN ${ }^{2}$, Michaël MANCA $^{2}$, \\ Patrick PRUNET $^{3}$ and Béatrice CHATAIN ${ }^{4}$ \\ 1 LERMA, INTECHMER/CNAM, BP 324, 50103 Cherbourg Cedex, France \\ 2 Ifremer, Laboratoire Ressources halieutiques, place Gaby Coll, BP 7, 17137 L'Houmeau, France \\ 3 INRA-SCRIBE, Fish Biology of Stress and Adaptation Group, 35042 Rennes Cedex, France \\ ${ }^{4}$ Station expérimentale d'aquaculture, Ifremer, Laboratoire de recherche piscicole de Méditerranée, Chemin de Maguelone, \\ 34250 Palavas-Les-Flots, France
}

Received 5 December 2012; Accepted 15 March 2013

\begin{abstract}
Replacing aquaculture feeds based on fisheries-derived resources with plant-based diets could be a relevant strategy to improve the sustainability of aquaculture. Recent studies on sea bass have shown that the total and early replacement of marine products by plant products would have a moderate effect on fish growth and body lipid content. Whether a plant-based diet impacts behavioural and physiological traits possibly linked to fish welfare, is not known, however. Here, we studied the effect of a totally plant-based diet introduced at an early stage of sea bass development on self-feeding behaviour, learning ability in a T-maze and stress biomarkers. We first compared learning processes in selffeeding conditions, between naive fish fed a plant-based diet (PBF) and fish fed a classic marine diet (MF). Then, we tested fish individually in a T-maze to compare the two feed groups for swimming activity, exploration and the ability to learn to discriminate between two two-dimensional objects associated with a reward. Blood physiological variables, including stress indicators (cortisol and glucose concentrations), were also determined. We did not find any indications of differences in self-feeding behaviour between PBF and MF in the first 30 days. A second experiment showed similar swimming activities in both fish categories. The "no-choice" percentage was high in both fish categories ( 60\%), but all the fish moved preferentially toward the reward. Their first turns indicated an ability to discriminate between two two-dimensional objects to complete a simple task. However, the high percentage of "no-choice" responses in both fish categories could have rendered the results non significant. The T-maze test procedure induced the production of high concentrations of cortisol, indicating acute stress in fish of both groups during testing. Plasma cortisol concentration was higher in MF than PBF, suggesting that the plant-based diet may affect the short-term release of cortisol. This study provides the first insight into the impact of a plant-based diet on sea bass behavioural traits, and confirms the effect of this diet on cortisol release in response to stress. Overall, in this first experiment, we did not find any major impact of a plant-based diet on sea bass behavioural traits, which is an interesting point for the development potential of such a sustainable aquaculture strategy.
\end{abstract}

Keywords: Self-feeder / Plant-based diet / Learning / Exploratory behaviour / Cortisol / Dicentrarchus labrax

\section{Introduction}

Aquaculture is currently the fastest growing sector of animal production for food (FAO 2008, State of World Aquaculture), but it faces major challenges relating to the responsible development of farming activities. The sustainability of aquaculture depends largely on decreasing the current reliance on feeds based on ingredients derived from wild fishery resources. Increases in the prices of fish meal and fish oil could undermine the profitability of many aquaculture enterprises (Tacon 1998). This need has led to new lines of research

a Corresponding author: david. benhaim@cnam.fr aiming to develop substitutes for these feed ingredients. Several studies have shown that, at least in salmonids, it is possible to replace fish oil entirely with plant oil without affecting growth or feed conversion rates (Reinitz and Yu 1981; Hardy et al. 1987; Thomassen and Rosjo 1989; Greene and Selivonchick 1990; Guillou et al. 1995). Similar results were obtained for the total replacement of fish meal with plant proteins (Watanabe et al. 1998; Kaushik et al. 2004). In the European sea bass (Dicentrarchus labrax), 50 to $98 \%$ of the fish meal in the diet can be replaced with plant protein sources, with the maintenance of fish growth at rates similar to those observed when fish oil is used as the source of lipids (Kaushik et al. 2004; Dias et al. 2009), although the total replacement 
of fish meal with single plant protein sources has been shown to lead to slower growth in some cases (Dias et al. 2009). The replacement of $60 \%$ of the fish oil in the diet with plant oil has been shown to have no negative impact on the survival, growth or health of European sea bass (Izquierdo et al. 2003; Figueiredo-Silva et al. 2005; Mourente et al. 2005), but higher levels of substitution ( $80 \%$ ) resulted in poorer growth performances (Mourente et al. 2005).

A totally plant-based diet may also affect traits other than growth performance. Such substitution has been shown to modify muscle fatty acid composition (Thomassen and Rosjo 1989; Greene and Selivonchick 1990; Arzel et al. 1994). The inclusion of plant oil in fish feed can lead to changes in the fatty acid profile, with a decrease in the level of longchain polyunsaturated fatty acids (LC-PUFA), particularly eicosapentaenoic acid (EPA) (Izquierdo et al. 2003; Montero et al. 2005). In some cases, such changes may have a significant effect on the quality and sensory characteristics of fish fillets (Guillou et al. 1995; Martínez-Llorens et al. 2007), and effects on active odour compounds are also possible (Serot et al. 2001; Serot et al. 2002). Finally, the inclusion of linseed oil in the diet, replacing between $60 \%$ and $100 \%$ of the anchovy oil present in the original diet, increases plasma cortisol concentrations in sea bream (Sparus aurata) exposed to acute confinement stress (Montero et al. 2003; Ganga et al. 2011).

Investigation of the potential of plant oil for use as the sole lipid source in feed for marine fish has been limited up to now because the conversion of plasma linolenic acids into essential fatty acids arachidonic acid, eicosapentaenoic (EPA) and docosahexaenoic acid (DHA) is inefficient in these species (Sargent et al. 2002). However, a recent study showed a genotype-diet interaction effect on the growth of European sea bass that had been fed diets based on plant-based products alone, suggesting that extreme changes in diet and the use of plant-based products may have an impact on genetic improvement with respect to growth (Le Boucher et al. 2011).

It is not known, however, whether a plant-based diet impacts behavioural and physiological traits possibly linked to fish welfare A major challenge is that certain essential fatty acids, such as the DHA, only exist in the marine feed. A number of studies indicate that this fatty acid could be important for behavioural development. A plant-based diet reduced the swimming activity of seabream larvae (Benítez-Santana et al. 2007) and the development of schooling behaviour and brain development of yellowtail (Seriola quinqueradiata). For small mammals, such as rat (Rattus norvegicus), the lack of DHA reduced learning and memory capacity (Moriguchi et al. 2000; Lim et al. 2005), while mice (Mus musculus) became more anxious (Owada et al. 2006).

The aim of this exploratory study was to assess potential effects on sea bass behaviour of a totally PB diet initiated early in development. This study forms part of a larger research program investigating the heritability of growth performance in sea bass fed a totally PB diet and other aspects, such as the biochemical composition of tissues and physiology (e.g., osmoregulatory capacity).

We carried out two different experiments. In the first, we compared the learning process in self-feeding conditions between fish fed a totally plant-based diet (PBF) and fish fed a classic marine diet (MF). This species has been shown to be highly plastic and to have a considerable ability to learn to press a lever to receive a food reward (Anthouard et al. 1993; Covès et al. 1998; Covès et al. 2006; Millot et al. 2008). In this experiment, we focused on the first 30 days, as self-feeding activity reaches satisfactory levels within 22 days in this species (Sánchez-Vázquez et al. 1994).

In the second experiment, we compared some aspects of behaviour and cognition of fish (PBF vs. MF) tested individually in a T-maze. Fish are known to display a rich array of sophisticated behaviours, and several studies have shown that they have long-term memories and that learning plays a crucial role in their behavioural development (Brown et al. 2007).

In this study, we particularly focused on swimming activity, exploration and the ability to learn to discriminate between two two-dimensional objects, one associated with a reward (by visual contact with an unfamiliar congener, see Benhaïm et al. 2013 for further details) and the other with no reward. Finally, we also analysed various plasma physiological parameters, including the concentrations of stress biomarkers.

\section{Materials and methods}

\subsection{Fish}

The fish used here were hatched and grown at the Ifremer aquaculture station (Palavas-les-Flots, France). They were produced from wild-caught West Mediterranean European sea bass broodstock. A full factorial mating design was used to generate 225 families from nine dams and 25 sires. All fish were reared in the same tank, from the egg stage to almost three months old $(2.5 \mathrm{~g})$. The fish were fed Artemia for the first 40 days, and were then weaned onto classic marine-based artificial feed until they reached $2.5 \mathrm{~g}$. From this stage, 3000 individuals were fed an entirely plant-based (PB) diet - and 3000 were fed a classic marine (M) diet (Table 1). When the fish reached a mean body weight of $20 \mathrm{~g}$, they were tagged with passive integrated transponder PIT tag (EG-Id, Ulm, Germany) and assigned to three classes on the basis of growth performance (low, medium and high growth rates). At the end of the feeding period, 300 individuals from the medium growth-rate class in each diet category (where all families were equally represented) were transferred to the Ifremer experimental station at L'Houmeau (France) for behavioural and physiological characterization.

\subsection{Experiment 1: self-feeding behaviour in PBF vs. MF}

Immediately after their arrival at L'Houmeau, MF were randomly distributed among three tanks (50 fish per tank, tanks 1, 2 and 3), and PBF among three other tanks (60 fish per tank, tanks 4, 5 and 6) held in a single experimental room, described below. The number of fish studied was determined so as to take into account the difference in the weight of MF and $\mathrm{PBF}$ at the beginning of the experiment (mean $\pm \mathrm{SD}, 147 \pm 31 \mathrm{~g}$ and $93 \pm 29 \mathrm{~g}$, respectively). The remainder of the fish were kept in other tanks for use in experiment 2. 
Table 1. Ingredients and proximate composition of the experimental diets. M: Fish meal and fish oil diet. PB: Plant-based diet (all fish meal and fish oil replaced by plant products).

\begin{tabular}{|c|c|c|}
\hline Diet & $\mathrm{M}$ & $\mathrm{PB}$ \\
\hline \multicolumn{3}{|l|}{ Ingredients $\left(\mathrm{g} \mathrm{kg}^{-1}\right)$} \\
\hline Fishmeal & 380.0 & \\
\hline Corn gluten meal & 180.0 & 200.0 \\
\hline Soybean meal & 0.0 & 182.0 \\
\hline Wheat gluten & 72.0 & 20.0 \\
\hline Extruded wheat & 253.0 & 72.0 \\
\hline White lupin & & 140.0 \\
\hline Fish oil & 85.0 & \\
\hline Linseed oil & & 94.0 \\
\hline Soya lecithin & & 10.0 \\
\hline L-lysine & & 27.0 \\
\hline $\mathrm{CaHPO}_{4} \cdot 2 \mathrm{H}_{2} \mathrm{O}$ & & 30.0 \\
\hline Binder (sodium alginate) & 10.0 & 10.0 \\
\hline Attractant $\operatorname{mix}^{\mathrm{a}}$ & & 15.0 \\
\hline Mineral premix ${ }^{b}$ & 10.0 & 10.0 \\
\hline Vitamin premix $^{\mathrm{b}}$ & 10.0 & 10.0 \\
\hline \multicolumn{3}{|l|}{ Chemical composition } \\
\hline Dry matter (DM, \%) & 88.9 & 94.5 \\
\hline Crude protein (\% DM) & 49.4 & 49.6 \\
\hline Crude fat $(\% \mathrm{DM})$ & 14.4 & 14.1 \\
\hline Ash (\% DM) & 7.0 & 6.1 \\
\hline Nitrogen-free extract $(\mathrm{NFE})(\% \mathrm{DM})^{\mathrm{c}}$ & 18.1 & 24.7 \\
\hline
\end{tabular}

a The attractant mix contained $3 \mathrm{~g} \mathrm{~kg}^{-1}$ taurine, $3 \mathrm{~g} \mathrm{~kg}^{-1}$ betaine, $2 \mathrm{~g} \mathrm{~kg}^{-1}$ glycine, $2 \mathrm{~g} \mathrm{~kg}^{-1}$ alanine and $5 \mathrm{~g} \mathrm{~kg}^{-1}$ glucosamine, ${ }^{\mathrm{b}}$ As in Guillaume et al. (2001), ${ }^{\mathrm{c}}$ NFE: Dry matter-crude protein-crude fat-ash).

Experiment 1 was thus carried out in six 400-L tanks supplied with filtered seawater in a recirculating system (flow rate: $4 \mathrm{~m}^{3} \mathrm{~h}^{-1}$ in each tank, and water renewal: $10 \%$ per day). Mean water temperature, oxygen concentration and salinity were measured throughout the experiment, which gave the following values: $21.2 \pm 0.8{ }^{\circ} \mathrm{C}, 7.6 \pm 1.4 \mathrm{mg} \mathrm{L}^{-1}$, and $23.2 \pm 1.4 \mathrm{~g} \mathrm{~L}^{-1}$, respectively. Black curtains were drawn around the tanks to limit visual disturbance, and each tank was lit by a single $120 \mathrm{~W}$ lamp positioned about $90 \mathrm{~cm}$ above the surface of the water. The light was switched on for $16 \mathrm{~h}$ and off for $8 \mathrm{~h}$ of each 24-h cycle (light switched on at 06:00 U.T. +1 ), with twilight transition periods of $30 \mathrm{~min}$. The fish were fed pellets, the composition of which is given in Table 1 . The two diets had similar protein (digestible protein: $43 \%$ of dry matter), lipid (fat: $13 \%$ of dry matter) and energy $\left(17 \mathrm{MJ} \mathrm{kg}^{-1}\right.$ ) contents. As the MF were larger than the PBF, we used pellets of different sizes for the two categories ( $6 \mathrm{~mm}$ for MF and 2.5 for PBF; see Le Boucher et al. 2011 for further details) for further details). Each tank was equipped with a self-feeder. The feeders were operated by a device consisting of a screenedtype sensor (a metal rod protected by a PVC cylinder surrounded by the PIT tag detection antenna, Covès et al. 2006) and a control box. Correct triggering of the device resulted in the fish being rewarded with pellets. The feed dispensers were regulated to distribute $0.7 \mathrm{~g} \mathrm{~kg}^{-1}$ for MF and $0.4 \mathrm{~g} \mathrm{~kg}^{-1}$ for $\mathrm{PBF}$ at each trigger actuation. The reward level constituted a compromise between minimising wastage and optimising feed allocation to the group. This set-up made it possible to monitor the apparent feed consumption (food quantity dispensed minus waste at the bottom of the tank and in the sediment trap) of each group (i.e., tank). Device triggering activity was monitored continuously over 30 days, and was only stopped for $48 \mathrm{~h}$ due to a technical problem. During this time (D16 and D17), there were no recordings and the fish fasted.

Before the 30-day experiment itself, the fish were subjected to a 10-day acclimation period, in which they were fed one daily meal by hand until apparent satiation. They were then transferred to the self-feeding conditions on day 1 (D1) of the experiment. Under these conditions, the fish had continuous access to food ( $24 \mathrm{~h}$ per day), even during tank cleaning and waste counting, from 10:00 to 11:00 (U.T. + 1). The experiment lasted 30 days in total, and fish were weighed and measured (after anaesthesia with $40 \mathrm{ppm}$ clove oil) at the start (D1) and end (D31).

Growth performance and feeding behaviour were assessed by evaluating the following variables:

- Total body length (BL, cm);

- Specific growth rate (SGR, \% increase in body weight per day):

$\mathrm{SGR}=100($ Ln BWf - Ln BWi) $/ t$;

where BWf and BWi are the final and initial body weights (BW, g), respectively, and $t$ is the time interval (number of days);

- Feed demand (FD, $\mathrm{g} \mathrm{kg}^{-1}$ of fish biomass);

- Food wastage (FW, g).

At the end of experiment (D31), all the fish were killed and their sex determined.

\subsection{Experiment 2: behaviour of MF and PBF in a T-maze}

Fish from the residual stock fed the $\mathrm{M}$ and $\mathrm{PB}$ diets were first anaesthetized with $40 \mathrm{ppm}$ clove oil, and 10 individuals from each category were selected two days before the observation period. Mean total length was $22.7 \pm 0.9 \mathrm{~cm}$ for the MF and $22.0 \pm 1.4 \mathrm{~cm}$ for the PBF; mean weight was $91 \pm 4.2 \mathrm{~g}$ for the MF and $73.5 \pm 0.7 \mathrm{~g}$ for the PBF. All PIT tag numbers were noted for each individual before transfer into one of two 400-L tanks. A stock of sea bass of similar size from another population and located in another tank (fish with which the tested individuals were not familiar) was used as the reward in the experiment, as sea bass are attracted to the presence of a congener. All these fish were fed one daily meal by hand until apparent satiation.

Fish were individually tested in a T-maze constructed from opaque white expanded PVC and transparent Plexiglas ${ }^{\circledR}$ (Fig. 1A). The start box was a $30 \times 40 \mathrm{~cm}$ rectangle separated from the rest of the T-maze by a removable transparent Plexiglas ${ }^{\circledR}$ wall. At the end of each arm of the T-maze, an aquarium $(60 \times 26 \mathrm{~cm}, 60 \mathrm{~L})$, continually aerated by a pump, was placed against a fixed transparent Plexiglas ${ }^{\circledR}$ wall. This Plexiglas ${ }^{\circledR}$ wall was located $2.6 \mathrm{~cm}$ beyond an extension of the line of the start box wall, to ensure that the tested fish could not see the reward before they turned to the left or the right in the T-maze. Four white plastic supports were used to 

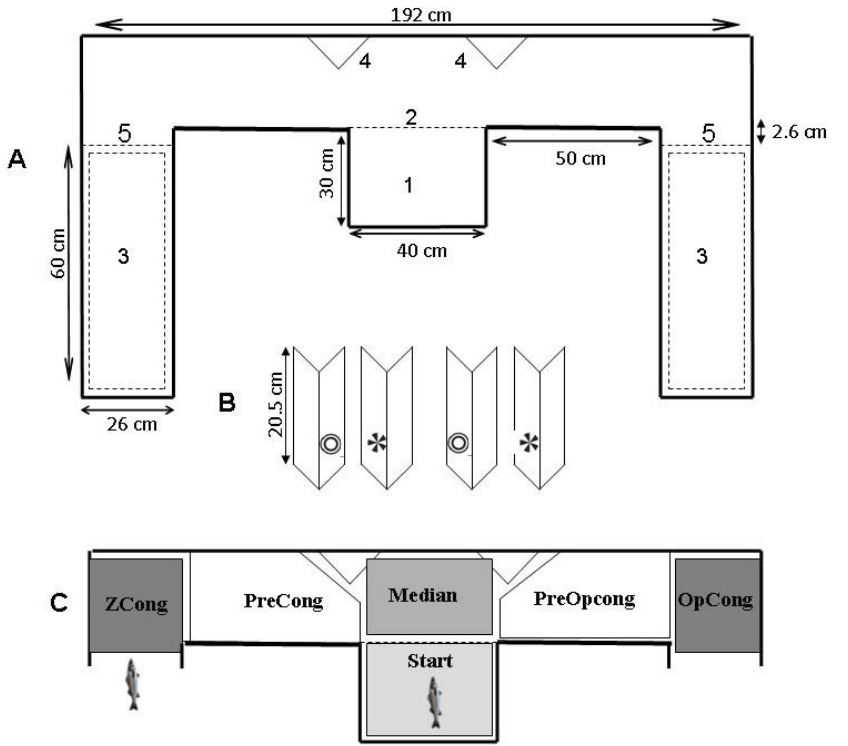

Fig. 1. A: Schematic diagram of the T-maze apparatus. Dotted lines are transparent Plexiglas ${ }^{\circledR}$ walls; continuous lines are opaque white plastic. 1. Start box; 2. Removable transparent Plexiglas ${ }^{\circledR}$ wall; 3. Aquarium in which the congener was placed; 4. White plastic support for laminated printouts of two-dimensional objects; 5. Fixed transparent Plexiglas ${ }^{\circledR}$ wall. B: Detail of the four supports and the two-dimensional objects. C: Delimitation of the virtual zones on the bottom of the T-maze for analysis of the video recordings. Example of a trial where the tested fish is shown in the start box, and the reward fish is shown on the left arm of the T-maze.

display two different laminated printouts of two-dimensional objects to the left or the right of the fish (Fig. 1B). Both objects (equal black and white areas) had already been successfully tested in a previous experiment (Siebeck et al. 2009). Shortly before the observations, the T-maze was filled with water to a level maintained at $20 \mathrm{~cm}$, corresponding to a total volume of $267 \mathrm{~L}$. Temperature, salinity and oxygen level were checked before and after each observation for each fish and the mean values obtained were $21.0 \pm 0.5{ }^{\circ} \mathrm{C}, 7.7 \pm 1.5 \mathrm{mg} \mathrm{L}^{-1}$, and $23.0 \pm 1.1 \mathrm{~g} \mathrm{~L}^{-1}$, respectively, before the observation and $21.0 \pm 0.4{ }^{\circ} \mathrm{C}, 7.6 \pm 1.4 \mathrm{mg} \mathrm{L}^{-1}$, and $23.0 \pm 1.2 \mathrm{~g} \mathrm{~L}^{-1}$, respectively, after the observation. A digital video camera (Imaging Source DMK 21AUO4) with a frame rate of $25 \mathrm{~Hz}$ and a resolution of $640 \times 480$ pixels was positioned $220 \mathrm{~cm}$ above the water surface. Three $80 \mathrm{~W}$ spot lights were placed around the T-maze to provide indirect, uniform lighting throughout it.

Before observation, one of the two-dimensional objects was randomly associated with the reward for each individual. The supports displaying the two-dimensional objects were also randomly positioned on the left or right arm of the T-maze, for each individual and each trial. The reward (an unfamiliar fish) was positioned to the left or right, as a function of the position of the associated two-dimensional object for the tested individual. Fish may choose to move towards an unfamiliar fish rather than a familiar fish for several reasons. First, two unfamiliar sea bass separated by a transparent barrier allowing visual contact only tend to spend most of their time in the zone nearest to the transparent barrier (Di-Poï 2008; Benhaïm et al. 2013). Second, the presence of a purely visual stimulus in this case seemed to have an effect on fish behaviour different from that of a chemical stimulus or a multimodal combination of both visual and chemical stimuli, resulting in the fish showing a greater interest in the presence of the congener on the other side of the transparent wall (Di-Poï 2008). The only constraint on the randomisation process was that the stimulus was not allowed to appear in the same position in more than two consecutive tests. The objects used were the most salient and detectable visual cues in the T-maze environment. The fish to be tested was gently collected from its tank, using a net, and transferred immediately to a covered bucket. It was then placed in the T-maze start box. The fish was allowed to acclimate to its surroundings for five minutes, after which the transparent wall was removed and video recording begun. The T-maze was filmed for $10 \mathrm{~min}$. The individual was then returned to the start box (pushing it gently with a net) and tested again after another five-minute acclimation period. In total, each individual underwent three consecutive tests per day with this procedure, repeated on five consecutive days. At the end of the three consecutive trials on a given day, the individuals were returned to their tanks. It took 14 days to test all the individuals. The water was entirely replaced at the end of each day and the unfamiliar fish used as the reward were replaced hourly, to minimise any stress they suffered due to confinement and handling.

\subsection{Video analysis}

The video recordings were analysed with EthoVision XT software (Noldus, The Netherlands), with which we defined six virtual zones in the T-maze (Fig. 1C) and tracked fish swimming behaviour.

We also analysed two learning criteria for each video: direction of the first turn of the fish (left or right) leading to the reward zone (success) or the other zone (failure), and the time taken to reach the reward zone or the other zone.

\subsection{Swimming behaviour}

We used several variables to analyse fish exploration and swimming behaviours:

- The time spent in each zone (in s): start box (Start), median area (Median), reward zone near the congener (ZCong), zone opposite to the reward zone (OpCong), zone located between Median and ZCong (PreCong) zones, zone located between the Median and OpCong (PreOpcong) zones.

- Absolute angular velocity of the fish, expressed in degrees per second $\left(\right.$ Vang,${ }^{\circ} \mathrm{s}^{-1}$ ) was calculated with the software as follows:

$$
\operatorname{Vang}_{n}=\mathrm{RTA}_{n} / t_{n}-t_{n-1},
$$

where $\mathrm{RTA}_{n}$ is the relative turn angle for sample $n$ and $t_{n}-t_{n-1}$ is the time difference between the current and the previous sample. The rate of change in direction is unsigned. The turn angle is calculated as the difference between two subsequent values for head direction. This variable serves as an indicator of the amount of turning per unit time and quantifies the complexity of the swimming path. 
- The distance travelled by each fish in the T-maze (Dtot, $\mathrm{mm})$.

- Mean velocity, expressed in body length per second (Vel, $\left.\mathrm{BL} \mathrm{s}^{-1}\right)$.

The last three of these variables was used to quantify the swimming activity of the fish in the T-maze.

\subsection{Fish learning process}

Several variables were used to assess the fish learning process:

- Number of successful and unsuccessful turning outcomes. We took only the very first turn made by the fish in a trial into account to determine success/failure. So, the maximum possible score is 14 successful turns (not 15 , because the first turn in the first trial cannot be counted as a success because it was not a learned choice) if the fish eventually went to the reward zone in the first trial, even if this was not after its first turning choice. Similarly, if the fish then went to the reward zone in the second trial, the maximum possible score would be 13 , and so on.

- The time taken to reach ZCong or OpCong (in second).

\subsection{Blood plasma analysis}

We compared physiological blood responses between MF and PBF by subjecting all individuals to an additional trial, performed as described above (experiment 2) but without filming. At the end of the trial, each fish was immediately anaesthetised with $40 \mathrm{ppm}$ clove oil, and a blood sample (about $1 \mathrm{ml}$ ) was collected from the caudal vessel with a 1-ml heparin-containing syringe (in less than $2 \mathrm{~min}$ ). A small aliquot of the blood sample was analysed immediately with an i-StatßPortable Clinical Analyser (Abbott; CG8+ cartridges; Heska Corporation, Fort Collins CO, USA, Harrenstien et al. 2005).

We analysed the following parameters:

- $\mathrm{pH}$;

- Carbon dioxide partial pressure $\left(\mathrm{pCO}_{2}, \mathrm{~mm} \mathrm{Hg}\right)$ and oxygen partial pressure $\left(\mathrm{pO}_{2}, \mathrm{~mm} \mathrm{Hg}\right)$;

- Base excess $\left(\mathrm{mmol} \mathrm{L}^{-1}\right)$;

- Bicarbonate concentration $\left(\mathrm{HCO}_{3}, \mathrm{mmol} \mathrm{L}^{-1}\right)$;

- Total carbon dioxide concentration (total $\mathrm{CO}_{2}, \mathrm{mmol} \mathrm{L}^{-1}$ );

- Oxygen saturation $\left(\mathrm{sO}_{2}, \%\right)$;

- Potassium ion concentration $\left(\mathrm{K}^{+}, \mathrm{mmol} \mathrm{L}^{-1}\right)$ and sodium ion concentration $\left(\mathrm{Na}^{+}, \mathrm{mmol} \mathrm{L}^{-1}\right)$;

- Ionised calcium (iCa, mmol L ${ }^{-1}$ );

- Plasma glucose concentration (Glu, $\mathrm{mg} \mathrm{dl}^{-1}$ );

- Haematocrit (Hct, or \% packed cell volume, PCV);

- Haemoglobin concentration $\left(\mathrm{Hb}, \mathrm{mmol} \mathrm{L}^{-1}\right)$;

- Cortisol (ng ml-1 $\mathrm{ng}^{-1}$.

The remainder of the blood sample was centrifuged at $3000 \times \mathrm{g}$ for $20 \mathrm{~min}$ at $4{ }^{\circ} \mathrm{C}$, and plasma samples were frozen and stored at $-80{ }^{\circ} \mathrm{C}$ until cortisol determinations, which were performed in duplicate for each individual. Cortisol $\left(\mathrm{ng} \mathrm{ml}^{-1}\right)$ determinations were carried out by means of a $3 \mathrm{H}$ cortisol radioimmunoassay, as described by Auperin et al. (1997).

Fish were finally killed by cervical section and their sex was determined.

\subsection{Statistical analysis}

All variables were compared between groups by analysis of variance (ANOVA), once the assumptions of normality and homoscedasticity had been confirmed (Dagnélie 1975). Significant ANOVA were followed by a post-hoc multiple comparison test (Newman-Keuls). All statistical analyses were carried out with Statistica 8 (Statsoft, USA) and $p<0.05$ was considered significant in all tests. Unless otherwise specified, results were expressed as average \pm standard error of the mean (SEM).

\section{Experiment 1}

Mean specific growth rate (SGR) was compared between the two categories of fish by ANOVA, with the treatment (PB vs. $\mathrm{M}$ diets) as a fixed factor and the tank as a random factor nested within treatment.

Feed demand and food wastage means were compared by ANOVA, with the treatment (PB vs. M diets) and period (2 periods of 15 days) as fixed factors and the tank as a random factor nested within treatment.

A $\chi^{2}$-test was used to compare the sex ratios for the two treatments.

\section{Experiment 2}

All variables related to swimming activity were compared by repeated measures analysis of variance, with treatment (PB vs. M diets) as a between-subject factor and trial (15 trials) as a within-subject factor.

For fish spatial distribution (time spent in each zone), since zones were not independent, a repeated measures analysis of variance was performed, with treatment (PB vs. M diets) as a between-subject factor and trial as a within-subject factor (15 trials) for each of the three following zones: ZCong, OpCong, Start. Then a null model of space use was tested: the fish spatial distribution was compared with a theoretical homogeneous distribution among ZCong, OpCong and Start (13\% in each zone) by a Kolmogorov-Smirnov test. The surfaces of other zones (Median, PreCong and PreOpcong) represented $63 \%$.

A binomial test with a 5\% level of significance was used to evaluate the proportions of successful/failed turns and preference for turn direction within each treatment.

All variables related to swimming activity were compared by repeated measures analysis of variance, with treatment (PB vs. M diets) as a between-subject factor and trial (15 trials) as a within-subject factor. 


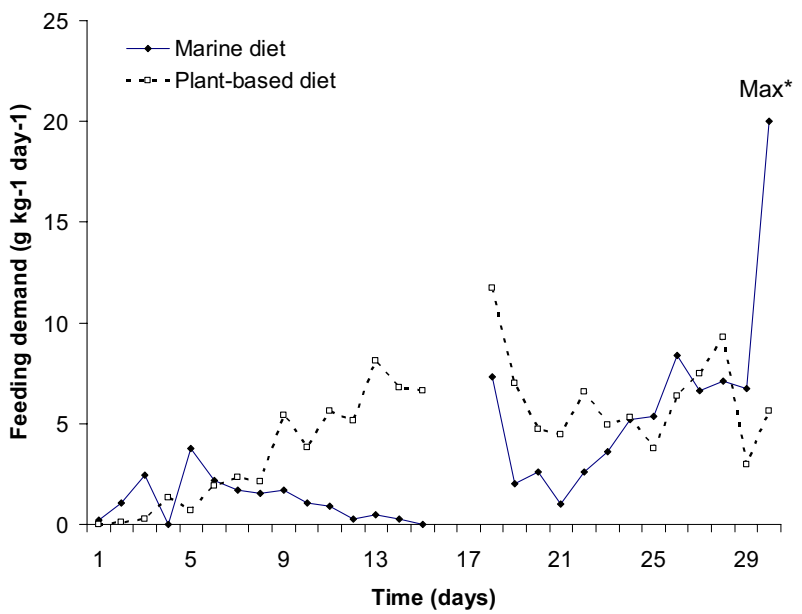

Fig. 2. Mean \pm SEM. Daily feeding demand during the experiment for fish fed a marine-based diet and fish fed a plant-based diet. (*) $33 \pm 18 \mathrm{~g} \mathrm{~kg}^{-1} \mathrm{day}^{-1}$.

The times taken to reach the reward zone were logtransformed and repeated measures analysis of variance was carried out, with treatment (PB vs. M diets) as a betweensubject factor and trial (15 trials) as a within-subject factor.

For physiological blood parameters and cortisol concentrations, data were first log-transformed, then ANOVA was carried out with treatment (PB vs. M diets) considered as an independent variable.

\section{Results}

\subsection{Experiment 1}

During the experiment, the mortality rate was $3.3 \pm 4.2 \%$ for MF and $8.3 \pm 5.0 \%$ for PBF, but this difference was not statistically significant $(N=3, Z=-1.5, p=0.13)$. On average, MF biomass per tank was (mean \pm SD) $7328 \pm 18 \mathrm{~g}$ at the beginning of the experiment and $7058 \pm 462 \mathrm{~g}$ at the end; for PBF, biomass was $5591 \pm 96 \mathrm{~g}$ at the beginning of the experiment and $4943 \pm 181 \mathrm{~g}$ at the end.

SGR did not differ significantly between treatments, but there was a significant tank(treatment) effect $\left(F_{(4,304)}=13.9\right.$, $p<0.001$ ), with one tank of PB fish (Tank 6) having a lower SGR than all the other tanks and one MF tank (Tank 2) having a higher SGR than all the other tanks ( $p<0.001$ in all pairwise comparisons). Most of the fish in all but one of the tanks (Tank 2, 29\%) had a negative SGR at the end of the period. We found that 61 and $74 \%$ of fish had a negative SGR in Tanks 1 and $3(\mathrm{MF})$ and that $71 \%, 73 \%$ and $95 \%$ of fish in the three PBF tanks had a negative SGR.

Feed demand was similar in PBF and MF (Fig. 2). No tank(treatment) or treatment effects were observed, but there was a highly significant period effect $\left(F_{(1,160)}=27.0\right.$, $p<0.001)$, with a higher FD in the second period than in the first $\left(6.3 \pm 0.4\right.$ and $2.3 \pm 0.2 \mathrm{~g} \mathrm{~kg}^{-1}$, respectively). No waste (FW) was observed in any of the tanks at any point in the experiment. The difference in sex ratio between the treatments was not significant $(87 \pm 2 \%$ male for MF and $82 \pm 3 \%$ male for PBF).

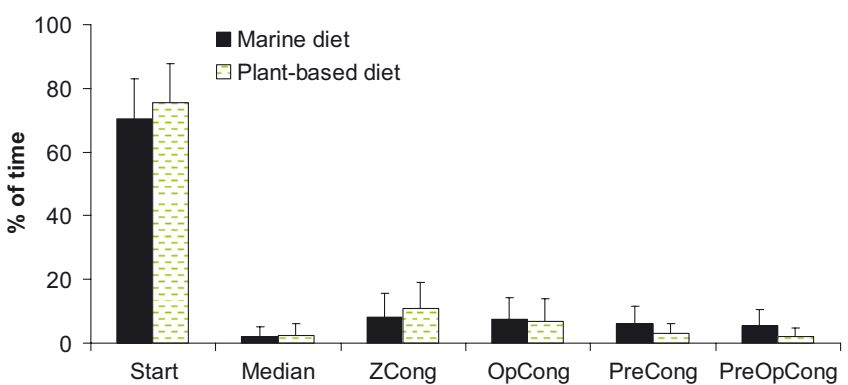

Fig. 3. Proportion of time spent (mean \pm SEM in \%) by fish fed a marine-based diet and fish fed a plant-based diet in each zone of the T-maze. Start: Start box; Median: Median area; ZCong: reward zone near the congener; OpCong: zone opposite the reward zone; PreCong: zone located between Median and ZCong; PreOpcong: zone located between Median and OpCong.

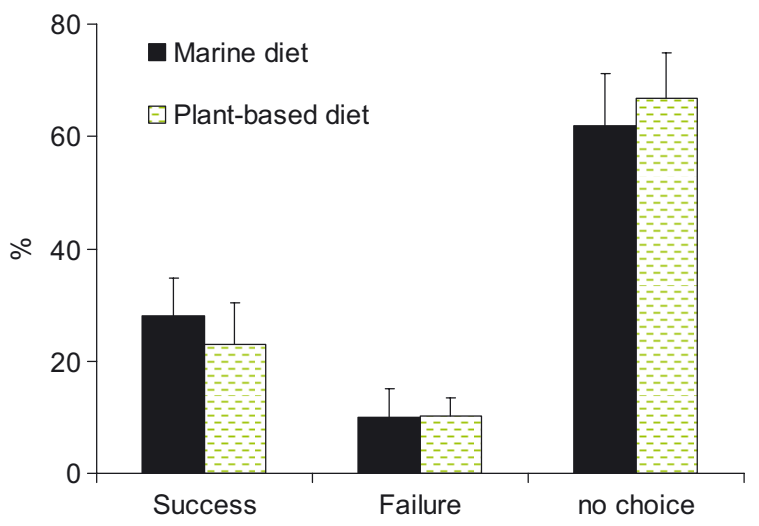

Fig. 4. Learning process assessment based on a comparison of the percentages of successful turns and turns resulting in failure of the test $($ mean $\pm \mathrm{SEM}$ in \%) in fish fed a marine-based diet and fish fed a plant-based diet.

\subsection{Experiment 2}

\section{Exploration and kinematics in the T-maze}

MF and PBF spent most of their time in the Start box $(71 \pm 12 \%$ and $76 \pm 12 \%$, respectively, Fig. 3$)$. The rest of the time, they were preferentially located in the reward zone near the congener ( $8 \pm 7 \%$ and $11 \pm 8 \%$, respectively) or in the zone opposite to the reward zone $(8 \pm 7 \%$ and $7 \pm 7 \%$, respectively). There were no significant differences between MF and PBF in their presence in any tested zones.

During all trials, the observed fish spatial distributions were different from the theoretical homogeneous spatial distributions ( $D=0.52, p<0.01$ for ZCong, OpCong and Start).

On average, MF had higher Dtot and Vel than PBF $\left(1038 \pm 385 \mathrm{~mm}, 0.08 \pm 0.03 \mathrm{BL} \mathrm{s}^{-1}\right.$ and $577 \pm 168 \mathrm{~mm}$, $0.05 \pm 0.02 \mathrm{BL} \mathrm{s}^{-1}$, respectively), but these differences were not significant. Vang did not differ significantly between MF $\left(793 \pm 120^{\circ} \mathrm{s}^{-1}\right)$ and $\operatorname{PBF}\left(887 \pm 114^{\circ} \mathrm{s}^{-1}\right)$.

\section{Learning performances}

Both MF and PBF had a larger number of successful turns than of turns leading to task failure (Fig. 4), but a significant 
Table 2. Blood plasma variables in fish fed a marine-based diet (MF) vs. fish fed a plant-based diet (PBF).

\begin{tabular}{|c|c|c|c|}
\hline Fish category & MF & $\overline{\mathrm{PBF}}$ & $p$ \\
\hline $\mathrm{pH}$ & $7.1 \pm 0.0$ & $7.2 \pm 0.0$ & 0.20 \\
\hline $\mathrm{pCO}_{2}(\mathrm{~mm} \mathrm{Hg})$ & $17.6 \pm 1.0$ & $19.3 \pm 1.3$ & 0.30 \\
\hline $\mathrm{pO}_{2}(\mathrm{~mm} \mathrm{Hg})$ & $29.0 \pm 2.8$ & $28.0 \pm 5.4$ & 0.80 \\
\hline Base excess $\left(\mathrm{mmol} \mathrm{L}^{-1}\right)$ & $-23.4 \pm 0.4$ & $-20.5 \pm 0.9$ & $0.01 *$ \\
\hline $\mathrm{HCO}_{3}\left(\mathrm{mmol} \mathrm{L}^{-1}\right)$ & $5.7 \pm 0.4$ & $7.3 \pm 0.3$ & $0.01 *$ \\
\hline Total $\mathrm{CO}_{2}\left(\mathrm{mmol} \mathrm{L}^{-1}\right)$ & $6.2 \pm 0.4$ & $8.0 \pm 0.4$ & $0.02 *$ \\
\hline $\mathrm{sO}_{2}(\%)$ & $34.7 \pm 6.1$ & $41.5 \pm 7.7$ & 0.41 \\
\hline $\mathrm{Na}\left(\mathrm{mmol} \mathrm{L}^{-1}\right)$ & $161.2 \pm 3.8$ & $157.9 \pm 1.9$ & 0.43 \\
\hline $\mathrm{K}\left(\mathrm{mmol} \mathrm{L}^{-1}\right)$ & $5.9 \pm 0.5$ & $5.3 \pm 0.6$ & 0.47 \\
\hline $\mathrm{iCa}\left(\mathrm{mmol} \mathrm{L}^{-1}\right)$ & $1.1 \pm 0.2$ & $1.0 \pm 0.1$ & 0.42 \\
\hline Glucose $\left(\mathrm{mg} \mathrm{dl}^{-1}\right)$ & $92.3 \pm 12.4$ & $83.8 \pm 7.9$ & 0.41 \\
\hline Het (\% PCV) & $22.0 \pm 2.4$ & $24.0 \pm 1.7$ & 0.68 \\
\hline $\mathrm{Hb}\left(\mathrm{mmol} \mathrm{L}^{-1}\right)$ & $7.5 \pm 0.8$ & $8.2 \pm 0.6$ & 0.68 \\
\hline Cortisol (ng ml ${ }^{-1}$ ) & $452.1 \pm 122.5$ & $343.9 \pm 18.7$ & $0.02 *$ \\
\hline
\end{tabular}

Results are means \pm standard error of the mean (SEM) of 10 fish for each treatment, $* p<0.05$.

association between the two-dimensional object and the reward was found for only two out of $10 \mathrm{MF}$ (100\% successful turns, $p=0.01 ; 80 \%$ successful turns, $p=0.04$, respectively) and one out of 10 PBF ( $85 \%$ successful turns, $p<0.01$ ). The proportion of "no-choice" responses exceeded $60 \%$ for both fish categories (Fig. 4).

The time taken to reach the reward zone (latency) was between 5 and $335 \mathrm{~s}$ in MF and 3.8 and $372 \mathrm{~s}$ in PBF. This difference was not significant $\left(F_{(15,3)}=3.8, p=0.15\right)$.

\section{Physiological variables}

The only differences in physiological variables recorded between treatments (Table 2) were a higher base excess for MF and a lower $\mathrm{HCO}_{3}$ and total $\mathrm{CO}_{2}$ in $\mathrm{MF}$ than in PBF. Cortisol concentration was significantly lower in PBF than in MF. All of the tested individuals except for one PBF were male.

\section{Discussion}

The aim of this study was to assess the potential impact on behaviour of the change of a totally plant-based diet early in sea bass development. We carried out a first experiment comparing the learning process in self-feeding conditions between two fish categories (MF and PBF) and a second experiment in which we compared the behaviour, cognition and physiology of fish tested individually in a T-maze. The first experiment showed that the plant-based diet had no effect on self-feeding behaviour. The second showed that the plant-based diet induced a few behavioural, cognitive and physiological differences in fish faced with a challenge, such as a T-maze.

\subsection{Self-feeding behaviour}

Self-feeding behaviour did not differ between PBF and MF during the first 30 days, suggesting a lack of effect of the plantbased diet on feed-demand behaviour and growth performance over the study period. The sea bass in this experiment had not previously used the self-feeding apparatus, and triggering activity began two to three days after the start of the experiment, which is somewhat earlier than reported in previous studies (Rubio et al. 2004; Covès et al. 2006; Millot et al. 2008). This time lag is known to differ between devices of different design (Rubio et al. 2004) and between species. However, feeddemand was lower than reported in previous studies, reaching about $6 \mathrm{~g} \mathrm{~kg}^{-1}$ during the second 15-day period. As pointed out by Kohbara et al. (2003), it takes time for food demand to reach satisfactory levels. The learning period was thus characterised by poor growth performance and, as previously reported by Millot et al. (2008), many individuals had a negative SGR. No food wastage was observed in any of the tanks during this period. Sex ratios were similar for the two treatments, with more than $80 \%$ of males in each category, consistent with the findings of previous studies on sea bass (Saillant et al. 2003). These results suggest that plant-based diets do not affect sex determination, unlike other environmental factors, such as temperature (Baroiller et al. 1999), or social interactions (Shapiro 1980).

\subsection{Swimming activity and spatial distribution}

Both differences and similarities in behaviour were found between MF and PBF. The distance travelled and mean velocity were higher in MF than in PBF, although these differences were not significant. Angular velocity was similar in $\mathrm{M}$ and PB fish, at a value close to that reported for a previous T-mazebased study (about $700^{\circ} \mathrm{s}^{-1}$, Benhaïm et al. unpublished data) indicating a lack of effect of plant-based diets on the complexity of the swimming path. The plant-based diet therefore does not seem to affect swimming activity dramatically.

We found that fish on both diets spent a large proportion of their time in the start box, whereas this was not the case in a similar study comparing wild and domesticated sea bass (Benhaïm et al. 2013). This may reflect the higher levels of stress in our study, in which the fish were much larger than those used in the previous study and may, therefore, have been more difficult to handle. The fish remained motionless in the start box for a large proportion of the time, which resembles the characteristic "freezing behaviour" described for fish subjected to stressful events (Malavasi et al. 2004; Millot et al. 2009). Once out of this zone, both categories of fish spent most of their time in the zone located near the congener and in the area on the opposite side. These findings are consistent with those of a previous study (Benhaïm et al. 2013) and suggest that the plant-based diet had no impact on exploration behaviour.

\subsection{Learning abilities}

When fish left the start box, they preferentially moved toward the congener zone, making their first turns in this direction. This result seems to indicate that they were able to discriminate between two two-dimensional objects. However, a significant association between the two-dimensional object and the reward was only observed for a very small number of 
individuals from the two categories. The significance of the results could be limited by the high proportion of "no-choice" responses for fish of both categories.

The best learning criterion was the first turn performed by the fish. As Alves et al. (2007) previously reported, latency did not appear to be a pertinent indicator in our study, due to the large differences between individuals. Successful individuals also displayed anticipatory behaviour, as most were oriented toward the correct stimulus before the wall was removed. Behaviour of this type has also recently been reported for cod (Gadus morhua) (Nilsson et al. 2008), in which it has been referred to as "goal tracking" (Siebeck et al. 2009). In our study, the fish that successfully completed the task clearly used a place strategy rather than a response strategy. In place strategies, animals learn to associate a given place with a reward (Dudchenko 2001; Gibson and Shettleworth 2005) while in response strategies, the animals find a goal through the use of a fixed sequence of actions (Restle 1957). Previous studies have shown that fish make use of multiple spatial strategies very similar to those described in mammals and birds (Lopez et al. 1999), but that a particular strategy may be favoured by the conditions of an experiment (Restle 1957).

The two categories of fish responded very similarly to the test. This indicates that a plant-based diet would not have a major effect on spatial orientation, such as place learning, in sea bass.

\subsection{Physiological traits}

Blood parameters determined after a single test in a T-maze were similar for both fish categories and were within the usual range of values for sea bass (Coeurdacier et al. 1997; Dosdat et al. 2003; Millot et al. 2008). Only base excess, $\mathrm{HCO}_{3}$ and total $\mathrm{CO}_{2}$ differed significantly between categories, but the values obtained did not indicate any major physiological disturbance. Glucose and ion $\left(\mathrm{Na}^{+}, \mathrm{Cl}^{-}\right.$and $\left.\mathrm{Ca}^{2+}\right)$ levels were similar in the two categories of fish and did not indicate any secondary stress induced by the test procedure, because they were within the range of resting values for sea bass (Cerdá-Reverter et al. 1998; Peruzzi et al. 2005; Di Marco et al. 2008). As already reported by Marino et al. (2001), the brief handling of sea bass induces no significant changes in these plasma parameters. We can therefore assume that the protocol used in experiment 2 was mild enough to have no effect on these plasma parameters. By contrast, the exposure of the fish to the test procedure resulted in high cortisol concentrations in both categories of fish $\left(\sim 450 \mathrm{ng} \mathrm{ml}^{-1}\right.$ in $\mathrm{MF}$ and $\sim 340 \mathrm{ng} \mathrm{ml}^{-1}$ in PBF). Published cortisol concentrations for unstressed sea bass range from 15 to $133 \mathrm{ng} \mathrm{m}^{-1}$ (Roche and Boge 1996; Cerdá-Reverter et al. 1998; Marino et al. 2001), suggesting that the test procedure used here induced a rapid increase in the concentration of this hormone in the blood. The test procedure included acute handling of the fish, which typically elicits a cortisol response in many species (Schreck 1982; Barton 2000). Moreover, the tested fish were subjected to isolation stress, which has also been shown to increase plasma cortisol concentration (Allen et al. 2009). These plasma cortisol concentrations probably indicate the development of an acute stress response in sea bass exposed to the protocol of experiment 2. This raises questions about the possible effects of this protocol on the comparison of behavioural responses between PBF and MF. Learning may also be impaired by such acute stress responses, as suggested by previous studies on rat in water mazes (Hölscher 1999) and on zebrafish (Danio rerio) in mazes (Gaikwad et al. 2011). One unexpected result of this study was the significantly lower cortisol concentrations in stressed PBF compared with stressed MF. This finding suggests that one of the major consequences of the plant-based diet is a lower level of cortisol release by the kidneys in response to acute stress. Previous studies on sea bream showed that the replacement of dietary fish oil with vegetable oils (such as linseed oil, but not soybean oil) led to significantly higher plasma cortisol concentrations after acute stress (Montero et al. 2003), and significantly higher levels of cortisol release by the head kidney after adrenocorticotropic hormone (ACTH) stimulation (Ganga et al. 2011). Similar results have also been shown in sunshine bass (Morone saxatilis) and cobia (Rachycentron canadum) fed reduced fish meal feeds (Laporte and Trushenski 2012; Trushenski et al. 2013). The replacement of fish oil with vegetable oils devoid of LCPUFA results in lower tissue concentrations of arachidonic acid, essential fatty acids and DHA (Ganga et al. 2011). Several studies have shown that these fatty acids can modulate cortisol release in fish (Van Anholt et al. 2004), although their mechanisms of action remain unclear (Ganga et al. 2006). We found that the manipulation of sea bass (catching in a net and transferring to the T-maze for $15 \mathrm{~min}$ ) led to acute stress, as indicated by the high cortisol concentrations in the plasma, although this cortisol response was weaker in fish fed a plantbased diet. Similar results have already been reported for sea bream in studies comparing animals fed linseed or soybean oil, with effects on cortisol release reported for linseed oil, but not for soybean oil (Ganga et al. 2011). Ganga et al. (2011) suggested that differences in the ratio of $n-3$ to $n-6$ fatty acids in the head kidney might account for such differences. In the absence of information about the LC-PUFA (of the $n-3$ or $n-6$ series) content of the head kidney in our fish, it is difficult to explain the differences between our data for sea bass and those reported for sea bream. Further studies are therefore required to clarify the underlying mechanisms. In conclusion, our data clearly confirm that plant-based diets have a significant effect on the responsiveness of the hypothalamic-pituitary-interrenal (HPI) axis to acute stress, as already suggested in other fish species (see review by Montero and Izquierdo 2010).

\subsection{Conclusion}

This study provides the first insight into the impact of the early introduction of a plant-based diet on sea bass behavioural traits and confirms the effect of this diet on cortisol release in response to stress. Interestingly, regarding the development potential of such sustainable aquaculture strategy, there were a lot of behavioural similarities between fish categories i.e., self-feeding behaviour, swimming activity and learning performances. Our findings for learning require confirmation by further studies with larger numbers of learning sessions and/or individuals and experiments designed to minimise stress and to make it possible to specify the spatial learning approach used 
(testing response vs. place learning). Our results for physiological traits, particularly cortisol concentrations indicate another impact of plant-based diets that is worthy of further study. Further studies carried out at an earlier stage, particularly during the transition from a marine to a plant-based diet, would also improve our understanding of the mechanisms underlying the differences in growth performance between fish fed a marine diet and fish fed a plant-based diet. Finally, we need to link behavioural, physiological and other traits, such as growth performance and survival, to confirm that sea bass fed a plantbased diet can really adapt to the challenges they are likely to face in their environment and that such diets are compatible with the welfare, quality and health of this species.

Acknowledgements. We thank Alain Vergnet from the Ifremer station at Palavas-les-flots for organising the transport of the fish and Richard Le Boucher for giving his advice throughout this project. We would also like to thank Claudiane Valotaire (INRA-SCRIBE, Fish Biology of Stress and Adaptation Group) for carrying out the cortisol determinations. We would finally like to thank Sandie Millot for statistical help. This study was approved by the Animal Care Committee of France under the official licence of M.L. Bégout (17-010).

\section{References}

Allen P.J., Barth C.C., Peake S.J., Abrahams M.V., Anderson W.G., 2009, Cohesive social behaviour shortens the stress response: the effects of conspecifics on the stress response in lake sturgeon Acipenser fulvescens. J. Fish Biol. 74, 90-104.

Alves C., Chichery R., Boal J.G., Dickel L., 2007, Orientation in the cuttlefish Sepia officinalis: response versus place learning. Anim. Cogn. 10, 29-36.

Anthouard M., Divanach P., Kentouri M., 1993, An analysis of feeding activities of sea bass Dicentrarchus labrax, Moronidae raised under different lighting conditions. Ichthyophysiol. Acta $16,59-70$.

Arzel J., Martinez Lopez F.X., Métailler R., Stéphan G., Viau M., Gandemer G., Guillaume J., 1994, Effect of dietary lipid on growth performance and body composition of brown trout (Salmo trutta) reared in seawater. Aquaculture 123, 361-375.

Auperin B., Baroiller J.-F., Ricordel J.F., Fostier A., Prunet P., 1997, Effect of confinement stress on circulating levels of growth hormone and two prolactins in freshwater-adapted tilapia (Oreochromis niloticus). Gen. Comp. Endocrinol. 108, 35-44.

Baroiller J.F., Guiguen Y., A.F., 1999, Endocrine and environmental aspects of sex differentiation in fish. Cell. Mol. Life Sci. 55, 910-931.

Barton B.A., 2000, Salmonid fishes differ in their cortisol and glucose responses to handling and transport stress. N. Am. J. Aquac. 62, 12-18.

Benhaïm D., Bégout M.-L., Chatain B., 2013, Unfamiliar congener used as a visual attractor in wild caught and domesticated sea bass (Dicentrarchus labrax) placed in a T-maze. J. Aquac. Res. Develop. doi : 10.4172/2155-9546.1000169

Benítez-Santana T., Masuda R., Carrillo E.J., Ganuza E., Valencia A., Hernández-Cruz C.M., Izquierdo M.S., 2007, Dietary n-3 HUFA deficiency induces a reduced visual response in gilthead seabream Sparus aurata larvae. Aquaculture 264, 408-417.

Brown C., Laland K., 2001, Social learning and life skills training for hatchery reared fish. J. Fish Biol. 59, 471-493.
Brown C., Laland K., Krause J., 2007, Fish Cognition and Behaviour. Blackwell Publishing Ltd. Fish Cognition and Behavior.

Cerdá-Reverter J.M., Zanuy S., Carrillo M., Madrid J.A., 1998, Timecourse studies on plasma glucose, insulin and cortisol in Sea Bass (Dicentrarchus labrax) held under different photoperiodic regimes. Physiol. Behav. 64, 245-250.

Coeurdacier J.L., Pepin J.F., Fauvel C., Legall P., Bourmaud A.F., Romestand B., 1997, Alterations in total protein, IgM and specific antibody activity of male and female sea bass (Dicentrarchus labrax L., 1758) sera following injection with killed Vibrio anguillarum. Fish Shellfish Immunol. 7, 151-160.

Covès D., Beauchaud M., Attia J., Dutto G., Bouchut C., Bégout M.L., 2006, Long-term monitoring of individual fish triggering activity on a self-feeding system: An example using European sea bass (Dicentrarchus labrax). Aquaculture 253, 385-392.

Covès D., Gasset E., Lemarié G., Dutto G., 1998, A simple way of avoiding feed wastage in European seabass, Dicentrarchus labrax, under self-feeding conditions. Aquat. Living Resour. 11, 395-401.

Dagnélie P., 1975, Théorie et méthodes statistiques. Applications agronomiques vol. 2. Presses Agronomiques de Gembloux, Gembloux.

Di-Poï C., 2008, Déterminisme de la structure sociale chez le bar juvénile Dicentrarchus labrax en conditions d'auto-nourrissage: Approches neuro-éthologique et physiologique. Thèse dr., Saint-Etienne.

Di Marco P., Priori A., Finoia M.G., Massari A., Mandich A., Marino G., 2008, Physiological responses of European sea bass Dicentrarchus labrax to different stocking densities and acute stress challenge. Aquaculture 275, 319-328.

Dias J., Conceicao L.E.C., Ribeiro A.R., Borges P., Valente L.M.P., Dinis M.T., 2009, Practical diet with low fish-derived protein is able to sustain growth performance in gilthead seabream (Sparus aurata) during the grow-out phase. Aquaculture 293, 255-262.

Dosdat A., Person-Le Ruyet J., Covès D., Dutto G., Gasset E., Le Roux A., Lemarié G., 2003, Effect of chronic exposure to ammonia on growth, food utilisation and metabolism of the European sea bass (Dicentrarchus labrax). Aquat. Living Resour. 16, 509-520.

Dudchenko P.A., 2001, How do animals actually solve the maze? Behav. Neurosci. 115, 850-860.

Figueiredo-Silva A., Rocha E., Dias J., Silva P., Rema P., Gomes E., Valente L.M.P., 2005, Partial replacement of fish oil by soybean oil on lipid distribution and liver histology in European seabass (Dicentrarchus labrax) and rainbow trout (Oncorhynchus mykiss) juveniles. Aquac. Nutr. 11, 147-155.

Gaikwad S., Stewart A., Hart P., Wong K., Piet V., Cachat J., Kalueff A.V., 2011, Acute stress disrupts performance of zebrafish in the cued and spatial memory tests: The utility of fish models to study stress-memory interplay. Behav. Process. 87, 224-230.

Ganga R., Montero D., Bell J.G., Atalah E., Ganuza E., Vega-Orellana O., Tort L., Acerete L., Afonso J.M., Benitez-Sanatana T., Vaquero A.F., Izquierdo M., 2011, Stress response in sea bream (Sparus aurata) held under crowded conditions and fed diets containing linseed and/or soybean oil. Aquaculture 311, 215-223.

Ganga R., Tort L., Acerete L., Montero D., Izquierdo M.S., 2006, Modulation of ACTH-induced cortisol release by polyunsaturated fatty acids in interrenal cells from gilthead seabream, Sparus aurata. J. Endocrinol. 190, 39-45.

Gibson B.M., Shettleworth S.J., 2005, Place versus response learning revisited: tests of blocking on the radial maze. Behav. Neurosci. $119,567-586$. 
Greene D.H., Selivonchick D.P., 1990, Effects of dietary vegetable, animal and marine lipids on muscle lipid and hematology of rainbow trout (Oncorhynchus mykiss). Aquaculture 89, 165-182.

Guillaume J., Kaushik S., Bergot P., Métailler R., 2001, Nutrition and feeding of fish and crustaceans. Springer-Praxis Publishing, Chichester.

Guillou A., Soucy P., Khalil M., Adambounou L., 1995, Effects of dietary vegetable and marine lipids on growth, muscle fatty acid composition and organoleptic quality of flesh of brook charr (Salvelinus fontinalis). Aquaculture 136, 351-362.

Hardy R.W., Scott T.M., Harrell L.W., 1987, Replacement of herring oil with menhaden oil, soybean oil, or tallow in the diets of Atlantic salmon raised in marine net-pens. Aquaculture 65, 267-277.

Harrenstien L.A., Tornquist S.J., Miller-Morgan T.J., Fodness B.G., Clifford K.E., 2005, Evaluation of a point-of-care blood analyzer and determination of reference ranges for blood parameters in rockfish. J. Am. Vet. Med. Assoc. 226, 255-265.

Hölscher C., 1999, Stress impairs performance in spatial water maze tasks. Behav. Brain Res. 100, 225-235.

Ishizaki Y., Masuda R., Uematsu K., Shimizu K., Arimoto M., Takeuchi T., 2001, The effect of dietary docosahexaenoic acid on schooling behaviour and brain development in larval yellowtail. J. Fish Biol. 58, 1691-1703.

Izquierdo M.S., Obach A., Arantzamendi L., Montero D., Robaina L., Rosenlund G., 2003, Dietary lipid sources for seabream and seabass: growth performance, tissue composition and flesh quality. Aquac. Nutr. 9, 397-407.

Kaushik S., Coves D., Dutto G., Blanc D., 2004, Almost total replacement of fish meal by plant protein sources in the diet of a marine teleost, the European seabass, Dicentrarchus labrax. Aquaculture 230, 391-404.

Kohbara J., Hidaka I., Matsuoka F., Osada T., Furukawa K., Yamashita M., Tabata M., 2003, Self-feeding behavior of yellowtail, Seriola quinqueradiata, in net cages: diel and seasonal patterns and influences of environmental factors. Aquaculture 220, 581-594.

Laporte J., Trushenski J., 2012, Production performance, stress tolerance and intestinal integrity of sunshine bass fed increasing levels of soybean meal. J. Anim. Physiol. Anim. Nutr. 96, 513-526.

Le Boucher R., Vandeputte M., Dupont-Nivet M., Quillet E., Mazurais D., Robin J., Vergnet A., Médale F., Kaushik S., Chatain B., 2011, A first insight into genotype-diet interactions in European sea bass (Dicentrarchus labrax L. 1756) in the context of plant-based diet use. Aquac. Res. 42, 583-592.

Lim S.Y., Hoshiba J., Moriguchi T., Salem J.N., 2005, N-3 fatty acid deficiency induced by a modified artificial rearing method leads to poorer performance in spatial learning tasks. Pediatr. Res. 584, 741-748.

Lopez J.C., Broglio C., Rodriguez F., Thimus-Blanc C., Salas C., 1999, Multiple spatial learning strategies in goldfish (Carassius auratus). Anim. Cogn. 2, 109-120.

Malavasi S., Georgalas V., Lugli M., Torricelli P., Mainardi D., 2004, Differences in the pattern of antipredator behaviour between hatchery-reared and wild European sea bass juveniles. J. Fish Biol. 65 (Suppl. A), 143-155.

Marino G., Di Marco P., Mandich A., Finoia M.G., Cataudella S., 2001, Changes in serum cortisol, metabolites, osmotic pressure and electrolytes in response to different blood sampling procedures in cultured sea bass (Dicentrarchus labrax L.). J. Appl. Ichthyol. 17, 115-120.

Martínez-Llorens S., Vidal A.T., Moñino A.V., Torres M.P., Cerdá M.J., 2007, Effects of dietary soybean oil concentration on growth, nutrient utilization and muscle fatty acid composition of gilthead bream (Sparus aurata L.). Aquac. Res. 38, 76-81.

Millot S., Bégout M.-L., Chatain B., 2009, Exploration behaviour and flight response toward a stimulus in three sea bass strains (Dicentrarchus labrax L.). Appl. Anim. Behav. 119, 108-114.

Millot S., Bégout M.-L., Person-Le Ruyet J., Breuil G., Di-Poï C., Fievet J., Pineau P., Roué M., Sévère A., 2008, Feed demand behavior in sea bass juveniles: effects on individual specific growth rate variation and health (inter-individual and intergroup variation). Aquaculture 274, 87-95.

Montero D., Kalinowski T., Obach A., Robaina L., Tort L., Caballero M.J., Izquierdo M.S., 2003, Vegetable lipid sources for gilthead seabream (Sparus aurata): effects on fish health. Aquaculture 225, 353-370.

Montero D., Robaina L., Caballero M.J., Ginès R., Izquierdo M.S., 2005, Growth, feed utilization and flesh quality of European sea bass (Dicentrarchus labrax) fed diets containing vegetable oils: a time-course study on the effect of a refeeding period with a $100 \%$ fish oil diet. Aquaculture 248, 121-134.

Montero D. , Izquierdo M., 2010, Welfare and health of fish fed vegetable oils as alternative lipid sources to fish oil. In: Turchini G.M., Ng W.K., Tocher R.D. (Eds.). Fish oil replacement and alternative lipid sources in aquaculture feeds. CRC Press, Taylor \& Francis, Boca Raton, FL.

Moriguchi T., Greiner R.S., Salem J.N., 2000, Behavioral deficits associated with dietary induction of decreased brain docohexaenoic acid concentration. J. Neurochem. 756, 2563-2573.

Mourente G., Dick J.R., Bell J.G., Tocher D.R., 2005, Effect of partial substitution of dietary fish oil by vegetable oils on desaturation and [beta]-oxidation of [1-14C]18:3n-3 and (LNA) and [1-14C]20:5n-3 (EPA) in hepatocytes and enterocytes of European sea bass (Dicentrarchus labrax L.). Aquaculture 248, 173-186.

Nilsson J., Kristiansen T.S., Fosseidengen J.E., Fernö A., van den Bos R., 2008, Sign- and goal-tracking in Atlantic cod (Gadus morhua). Anim. Cogn. 11, 651-659.

Owada Y., Abdelwahab S.A., Kitanaka N., Sakagami H., Takano H., Sugitani Y., Sugawara M., Kawashima H., Kiso Y., Mobarakeh J.I., Yanai K., Kaneko K., Sasaki H., Kato H., Saino-Saito S., Matsumoto N., Akaike N., Noda T., Kondo H., 2006, Altered emotional behavioral responses in mice lacking brain-type fatty acid-binding protein gene. Eur. J. Neurosci. 24, 175-187

Peruzzi S., Varsamos S., Chatain B., Fauvel C., Menu B., Falguière J.C., Sévère A., Flik G., 2005, Haematological and physiological characteristics of diploid and triploid sea bass, Dicentrarchus labrax L. Aquaculture 244, 359-367.

Reinitz G.L., Yu T.C., 1981, Effects of dietary lipids on growth and fatty acid composition of rainbow trout (salmo gairdneri). Aquaculture 22, 359-366.

Restle F., 1957, Discrimination of cues in mazes: A resolution of the "place-vs-response" question. Psychol. Rev. 64, 217-228.

Roche H., Boge G., 1996, Fish blood parameters as a potential tool for identification of stress caused by environmental factors and chemical intoxication. Mar. Environ. Res. 41, 27-43.

Rubio V.C., Vivas M., Sanchez-Mut A., Sanchez-Vazquez F.J., Coves D., Dutto G., Madrid J.A., 2004, Self-feeding of European sea bass (Dicentrarchus labrax L.) under laboratory and farming conditions using a string sensor. Aquaculture 233, 393-403.

Saillant E., Fostier A., Haffray P., Menu B., Laureau S., Thimonier J., Chatain B., 2003, Effects of rearing density, size grading and parental factors on sex ratios of the sea bass (Dicentrarchus labrax L.) in intensive aquaculture. Aquaculture 221, 183-206. 
Sánchez-Vázquez F.J., Martinez M., Zamora S., Madrid J.A., 1994, Design and performance of an accurate demand feeder for the study of feeding behaviour in sea bass, Dicentrarchus labrax L. Physiol. Behav. 56, 789-794.

Sargent J., Tocher D.R., Bell J.G., 2002, The lipids. In: Halver J.E., Hardy R.W. (Eds.), Fish Nutrition, Academic Press, San Diego, CA, pp. 59-66.

Schreck C.B., 1982, Stress and rearing of salmonids. Aquaculture 28, 241-249.

Serot T., Regost C., Arzel J., 2002, Identification of odour active compounds in muscle of brown trout (Salmo trutta) as affected by dietary lipid sources. J. Sci. Food Agric. 82, 636-643.

Serot T., Regost C., Prost C., Robin J., Arzel J., 2001, Effect of dietary lipid sources on odour-active compounds in muscle of turbot (Psetta maxima). J. Sci. Food Agric. 81, 1339-1346.

Shapiro D.Y., 1980, Serial female changes after simultaneous removal of males from social groups of a coral reef fish. Science 209, 1136-1137.

Siebeck U.E., Litherland L., Wallis G.M., 2009, Shape learning and discrimination in reef fish. J. Exp. Biol. 212, 2113-2119.
Tacon A., 1998, FAO aquaculture production update. Int. Aquafeeds 2, 13-16.

Thomassen M.S., Rosjo C., 1989, Different fats in feed for salmon: influence on sensory parameters, growth rate and fatty acids in muscle and heart. Aquaculture 79, 129-135.

Trushenski J., Schwarz M., Pessoa W.V.N., Mulligan B., Crouse C., Gause B., Yamamoto F., Delbos B., 2013, Amending reduced fish-meal feeds with marine lecithin, but not soy lecithin, improves the growth of juvenile cobia and may attenuate heightened responses to stress challenge. J. Anim. Physiol. Anim. Nutr. 97, 170-180.

Van Anholt R.D., Koven W.M., Lutzky S., Wendelaar Bonga S.E., 2004, Dietary supplementation with arachidonic acid alters the stress response of gilthead seabream (Sparus aurata) larvae. Aquaculture 238, 369-383.

Watanabe T., Verakunpiriya V., Watanabe K., Viswanath K., Satoh S., 1998 , Feeding of rainbow trout with non-fish meal diets. Fish Sci. 63, 258-266. 